\title{
e-Learning Tools on the Healthcare Professional Social Networks
}

\author{
Evgeny Nikulchev ${ }^{1}$, Dmitry Ilin $^{2}$, Bladimir Belov ${ }^{3}$ \\ MIREA-Russian Technological University \\ Moscow, Russia
}

\author{
Pavel Kolyasnikov ${ }^{4}$ \\ Russian Academy of Education \\ Moscow, Russia
}

\author{
Alexander Kosenkov ${ }^{5}$ \\ Sechenov First Moscow State Medical University \\ Moscow, Russia
}

\begin{abstract}
According to many studies, professional social networks are not widespread in the health care environment, especially doctors. The article is devoted to two advanced digital tools that can attract the image and increase motivation for professional social networks. The first tool is the inclusion of elearning, both to increase the level of knowledge and to confirm qualification skills among professionals. The second tool is the developed system of the formation of the tests constructor. The article describes solution of being developed Internet-resources for mass use in professional health care.
\end{abstract}

Keywords-Healthcare professional social networks; advanced digital tools; e-learning; test constructor; e-learning

\section{INTRODUCTION}

According to many researches, professional social networks are not widely disseminated in the health care environment [1]. One of the reasons for this seems to be the lack of special advanced digital tools [2,3] used in the practice of health protection and professional skills training.

There are established trends in the use of social networks. The most widely groups using them are nurses and medical students [4], while doctors are the least likely professional group that use social networks. The reasons for this seem to be inherent in the dichotomies of social technologies nature and the established patterns of doctor's decision-making [5]: it is argued that social technologies are built in accordance with the ideas of egalitarianism, weak ties, co-production and voluntary exchange with the intention of "encouraging a maximum of contributors and of getting the best number of contributions". However, in the professional field, it is necessary to attract not only idly interested, but specific specialists with certain skills and qualifications [6].

One of the common forms of the social networks use on an equal footing with job search is the increasing education level [7]. The inclusion of educational content into professional social networks can be attractive [8,9]. In addition, the presence of a certificate and training in a particular network makes the rest of the communication participants a sign of a professional standard, while now the skills are introduced quite arbitrarily [10], confirmed at best by other network participants, like it is in ResearchGate.
There is a wide range of health care professional social networks (HPSN) that are specifically designed for health care providers and the domain of health care. The article [11] shows a significant list of existing health-related HPSN. For the analysis and presentation of commonality and differences between HPSN the common and domain-specific functions can be identified. Common features mean a cohesive set of functionality that can be found in any form of HPSN, such as a personal profile, board, news board, chats, photo and video exchange, documents exchange (articles, presentations, reposts). Domain-specific functions are a set of functionalities that are specifically designed or might be of interest for health care professionals [2,12], such as a library of medical records or specialized workplaces for medical institutions [13]. In addition to some functional differences, the HPSN is also very different in terms of volume, access, and target groups of users. Although some platforms are open to health care workers around the world, some platforms restrict their access [14]. Some systems give an access to health a specific occupational group. Interprofessional and inter-genial collaboration and knowledge sharing can vary greatly between different HPSN.

Thus, the specificity of the HPSN is to use motivational mechanisms $[15,16]$ to attract users. It requires the development of reliable digital professional tools necessary for the practice.

The article describes solution of being developed Internetresources for mass use in professional health care. These are elearning system. The tool is including e-learning to Internetresources both for increasing the level of knowledge and confirming professional skills.

The paper consists of two sections, introduction and conclusions. Section II presents the results of developing a learning course for advanced training of cardiac surgeons, the course structure and the specifics of course creation. The Section III describes the developed methodology of tests creation for assessing the course completion. Tests are created in form of the algorithmic description language, which also allows the automatic web interfaces generation, using any modern popular device or browser. 


\section{E-LEARNING TOOLS}

The internal structure of social networks implies that each user of the network can choose the communication topics [17]. It means that there is no clear regulation or control over the topics [18] This is fundamentally contrary to the tasks of creating a professional communication service aimed at the professional and career development of medical specialists in accordance with the standards of their professional activities [19]. It is required to create a tool that allows specialists to improve their professional level, to form new skills and a system of encouragement for the career development of physicians, which would allow to create professional education in professional social networks. In the development process, a number of technological solutions were used [20, 21], in particular, for creating video lectures and recording operations.

To achieve the objectives and to answer the questions raised, following methods were used:

- questioning of physicians of different specialties (815 physicians) on the need and prospects of professional communication services in competence enhancing, career development and their participation in this service;

- questioning of medical specialists of different specialties (342 physicians) on the proper proportion of communication regulation in the professional communication process;

- theoretical research and enhancing the experience of the participation in a number of foreign and domestic social networks for common use;

- theoretical research and enhancing the experience of the participation in social networks for professional use, including the most popular LinkedIn и Gate Research;

- exploring the opportunities of the most common foreign and domestic software for digital learning management.

Methodical work was carried out based on the Department of Hospital Surgery at Sechenov First Moscow State Medical University. Service finalization and initial introduction are carried out with the help of the students of the department.

Currently, the basic implementation principles of professional communication service are developed. Communication in the service are regulated and implemented under centralized control. The issue of themes creating and professional communication level setting was resolved. The accounting, analyses and generalization of users' actions are carried out. Verified user authorization is being worked out.

Management and moderation of every communication topic is carried out by its leader. The leader is one of the professors on the Department of Hospital Surgery at Sechenov First Moscow State Medical University. The topics choice is currently being carried out by the same Department.

The topics are isolated from each other according to the theme. At the beginning, users have to study theory with using video-lecture and their fragments or reading. Users successfully studied the theory are allowed to complete tests. Tests are divided into two sections: question sets for every part of the topic and questions for the whole topic. After successful tests completion users can communicate with other users and the topic leader. They can ask some questions, share their experience or best practices. The overall sequence of the study and discussion is given on the example of the "Example of professional topic studying and discussing with the use of developed service" (Table I).

Examples of training system screens are shown in Fig. 1 and 2.

Service processes are implemented in Moodle, LMS open source software. So, its functional flexibility and additional features were used.

Methodical work was carried out based on the Department of Hospital Surgery at Sechenov First Moscow State Medical University. Service finalization and initial introduction are carried out with the help of the students of the department.

The material for service was collected with the help of well-organized and delivered video production (video lectures, their fragments, video records of surgical operations, etc.).

In our view, professional communication implemented in such form can be an effective tool for professional and career development of medical specialists, increasing their level of competence and enhancing their skills.

In the future, the service can be used for professional medical specialists' accreditation process that is used in different countries.

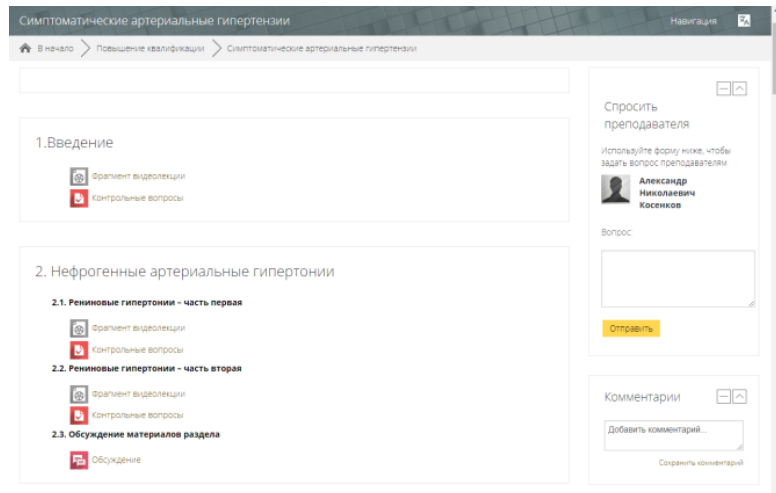

Fig. 1. Example of a Training Course.

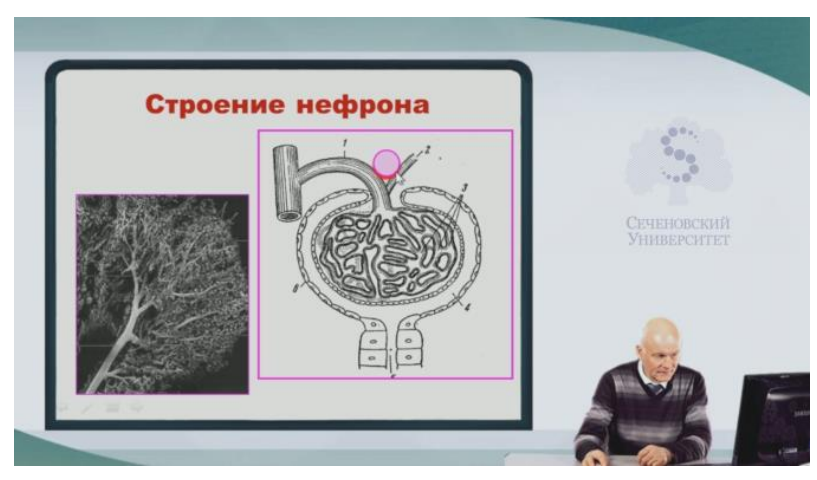

Fig. 2. Example of a Lecture. 
TABLE I. EXAMPLE OF PROFESSIONAL TOPIC STUDYING AND DisCUSSING WITH THE USE OF DEVELOPED SERVICE

\begin{tabular}{|c|c|c|c|c|c|c|}
\hline $\begin{array}{c}\text { Topic } \\
\text { number }\end{array}$ & $\begin{array}{l}\text { Fragments for video viewing of } \\
\text { theory }\end{array}$ & $\begin{array}{l}\text { References on } \\
\text { the topic }\end{array}$ & Testing by subtopics & $\begin{array}{l}\text { Discussions under the } \\
\text { subtopics }\end{array}$ & $\begin{array}{l}\text { Integration testing on } \\
\text { the topic }\end{array}$ & $\begin{array}{c}\text { Integration } \\
\text { discussion of the } \\
\text { topic }\end{array}$ \\
\hline 1. & Introduction & & - & - & & \\
\hline \multirow[b]{2}{*}{2.} & renin hypertension - first part & & \multirow{2}{*}{$\begin{array}{c}* \\
\text { link to testing for } \\
\text { subtopic «2» }\end{array}$} & \multirow{2}{*}{$\begin{array}{c}* \\
\text { link to forum for } \\
\text { subtopic «2» }\end{array}$} & & \\
\hline & renin hypertension - second part & & & & & \\
\hline \multirow{5}{*}{3.} & $\begin{array}{c}\text { Renovascular hypertension definition } \\
\text { (RVHT) }\end{array}$ & & \multirow{5}{*}{$\begin{array}{l}\text { link to testing for } \\
\text { subtopic «3» }\end{array}$} & \multirow{5}{*}{$\mid \begin{array}{c}* \\
\text { link to forum for subtopic } \\
\ll 3 »\end{array}$} & & \\
\hline & RVHT diagnostics - first part & & & & & \\
\hline & RVHT diagnostics - second part & & & & & \\
\hline & RVHT treatment & & & & & \\
\hline & RVHT clinical example & & & & & \\
\hline \multirow[t]{2}{*}{4.} & $\begin{array}{l}\text { Neurogenic arterial hypertension, } \\
\text { hypercapnia acidosis, exogenous } \\
\text { arterial hypertension }\end{array}$ & \multirow{10}{*}{$\begin{array}{l}* \\
\text { reference to } \\
\text { the list of } \\
\text { references on } \\
\text { the topic }\end{array}$} & $\begin{array}{c}* \\
\text { link to testing for } \\
\text { subtopic } « 4 »\end{array}$ & $\begin{array}{c}* \\
\text { link to forum for } \\
\text { subtopic «4» }\end{array}$ & & \\
\hline & $\begin{array}{c}\text { Arterial hypertension in adrenal cortex } \\
\text { tumor - first part }\end{array}$ & & \multirow{4}{*}{$\begin{array}{l}\text { link to testing for } \\
\text { subtopic «5» }\end{array}$} & \multirow{4}{*}{$\begin{array}{c}* \\
\text { link to forum for } \\
\text { subtopic } \ll 5 »\end{array}$} & \multirow{6}{*}{-} & \multirow{6}{*}{-} \\
\hline \multirow{3}{*}{5.} & $\begin{array}{c}\text { Arterial hypertension in adrenal cortex } \\
\text { tumor - second part }\end{array}$ & & & & & \\
\hline & $\begin{array}{l}\text { Arterial hypertension in } \\
\text { hyperthyroidism and } \\
\text { hyperparathyroidism }\end{array}$ & & & & & \\
\hline & Arterial hypertension in acromegalia & & & & & \\
\hline \multirow[b]{2}{*}{6.} & $\begin{array}{c}\text { Arterial hypertension in insufficiency } \\
\text { of aorta valve }\end{array}$ & & \multirow{2}{*}{$\begin{array}{c}* \\
\text { link to testing for } \\
\text { subtopic «6» }\end{array}$} & \multirow{2}{*}{$\begin{array}{c}* \\
\text { link to forum for } \\
\text { subtopic } « 6 »\end{array}$} & & \\
\hline & $\begin{array}{c}\text { Arterial hypertension in atherosclerosis } \\
\text { and coarctation of aorta }\end{array}$ & & & & & \\
\hline \multirow{3}{*}{7.} & Postsurgical arterial hypertension & & \multirow{3}{*}{ - } & \multirow{3}{*}{-} & \multirow{3}{*}{$\begin{array}{l}* \\
\text { link to testing for the } \\
\text { whole topic }\end{array}$} & \multirow{3}{*}{$\begin{array}{l}* \\
\text { link to the topic- } \\
\text { integrated forum }\end{array}$} \\
\hline & Diagnostic formulation & & & & & \\
\hline & Summarizing & & & & & \\
\hline
\end{tabular}

\section{TESTS CONSTRUCTOR}

The digital approach to tests allows expanding the list of tools available to the learning.

The software implementation for the survey is a webinterface for each test questionnaire included in the methodology. At the same time, an important feature is the need for cross-platform operation of interfaces [22], providing the ability to conduct surveys on a wide range of devices, popular browsers and operating systems Windows, Linux, MacOS, iOS, Android. The report is devoted to the developed standard for describing the interface elements of polls and the corresponding generation technologies on various systems.

For the platform-independent implementation of the testquestionnaire, an internal standard for presenting the test in a structured form has been developed. It allows using the structure to create a test interface based on previously created elements that have been developed and tested on various devices and operating systems. The presence of the standard makes it possible to develop an interactive designer of test questionnaires to automate the creation of new tests. The developed algorithmic standard for describing the elements includes general test settings (global settings) and consists of three main levels: test, block, and page.

Surveys can be viewed as a hierarchy consisting of three key levels:

1) Test (Fig. 3).

2) Block (fig. 4).

3) Page (Fig. 5). 
The test (Fig. 3) is the root element of the hierarchy, consists of one or more blocks, and also has settings related to the entire test as a whole. These settings include, for example, the language of the interface elements.

A block (Fig. 4) is a structure that combines one or more pages that have common parameters. The need to introduce this level of hierarchy will be discussed further on the example of two methods. The parameters of the block, for example, include:

1) The number of items that will be displayed on one page (items per page). Using this parameter can make it easier to split a large list of questions into equal parts.

2) The order of displaying questions and elements of instructions (items order). There are two main options: fixed and random order.

3) Progress display(show progress bar) adjusts whether to show or not to show the percentage of questions in the test.

4) Timer display (show timer). It implies three options: no timer, stopwatch and countdown.

5) Time limit for passing the block (expected time). If the participant does not fit in the allotted time, it will be asked to proceed to the next block of questions.

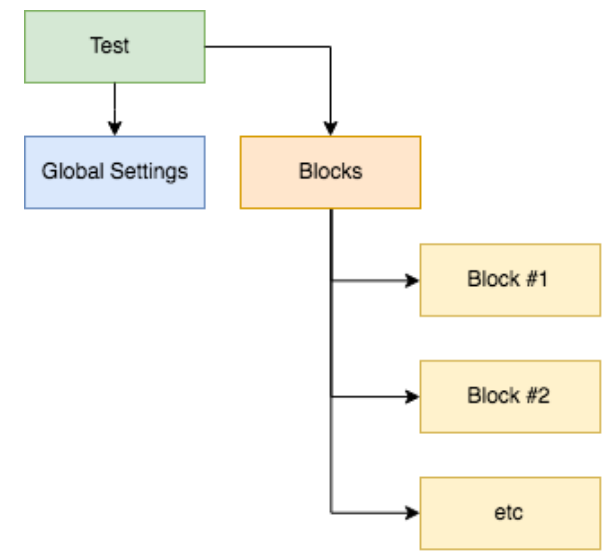

Fig. 3. Hierarchical Representation of the Test.

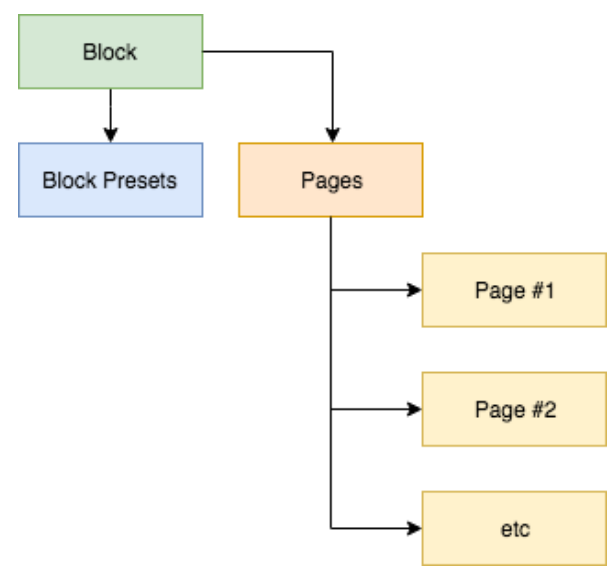

Fig. 4. Hierarchical Block Representation in Test.

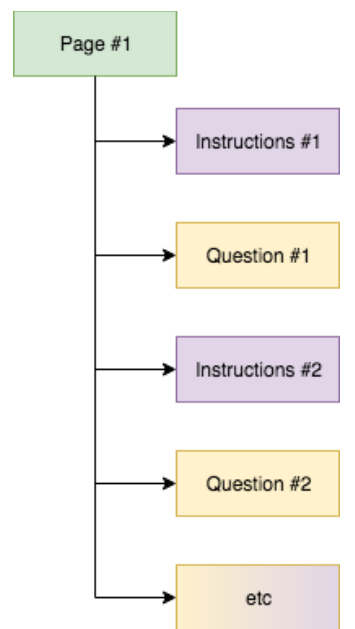

Fig. 5. Hierarchical Presentation of the Page in the Test Block.

A page (Fig. 5) is a collection of elements that directly represent the content of the survey. The page may contain elements of instructions and questions. The elements of the instruction include text blocks and media files presented to the participant.

The software implementation for the survey is a webinterface for each questionnaire included in the methodology. At the same time, it is worth to implement a cross-platform software [1] with providing the ability to conduct surveys on a wide range of devices, popular browsers and operating systems like Windows, Linux, MacOS, iOS, Android. The paper is devoted to the developed standard for describing the interface elements of surveys and the corresponding technologies of generation on different systems.

For the platform-independent implementation of the testquestionnaire, an internal standard for presenting the test in a structured form has been developed. It allows using the structure to create a test interface based on previously created elements that were developed and tested on different devices and operating systems. The standard makes it possible to develop an interactive designer of test questionnaires for creating new tests automatically.

The developed algorithmic standard for describing the elements includes general test settings (global settings) and consists of 3 levels: block, page and question (Fig. 3). Fig. 3 shows the upper level of the standard, which includes the general settings and blocks. The block is necessary to combine questions on their common behavior and display parameters. Each block includes one or more pages. The block structure is shown in Fig. 4. A page is a set of questions and instructions that are displayed together. A diagram of the general structure of the test-questionnaire page is shown in Fig. 5. The question is the basic unit of information that allows receiving and saving the result of the answer. Questions are divided into simple and composite. The answer to a simple question will be saved by a single unique key. A composite question implies more than one answer. Therefore, it will be saved by several different keys. 
To carry out calculations based on the answers to questions during data collection, a problem-oriented language was developed. The language includes the following groups of functions:

- Logical functions (and, or, not).

- Comparison functions (equal, greater than, etc.)

- Higher-order functions (map, reduce, etc.)

- Mathematical functions (add, subtract, etc.)

- Functions for working with vectors (sum, size, etc.)

- Data getting functions (getAnswers, getScale, etc.)

According to the developed structure, tests-questionnaires are presented in form of a document with hierarchical links. To form the resulting structure, the JSON Schema solution [23] was chosen, which is the standard for describing the structure of JSON documents.

Fig. 6 shows an example of the questionnaire implementation. On the left, a section of the test structure in JSON Schema, and on the right, an automatically constructed interface based on the described structure is shown.

To solve the problem of correctly displaying interface elements on devices with different screen sizes and image formats, an approach is used that allows automatically adjusting the content to any screen width. This approach is called Responsive Web Design, it rebuilds the interface structure to any screen width due to the pre-written rules in HTML and CSS. A web page can even adapt to a new device with a non-standard resolution.

As a result, a technology was implemented that allows creating a cross-platform interface that works in most modern web browsers and on different types of devices. Fig. 7 shows an example of displaying a questionnaire on different devices: tablet's display is shown on the left side and Android smartphone with Google Chrome browser is on the right side.

The use of technology based on the generation of the interface in accordance with the standard structure of the test description simplifies the process of implementing changes to the interface, since any corrections will be valid for all developed elements.

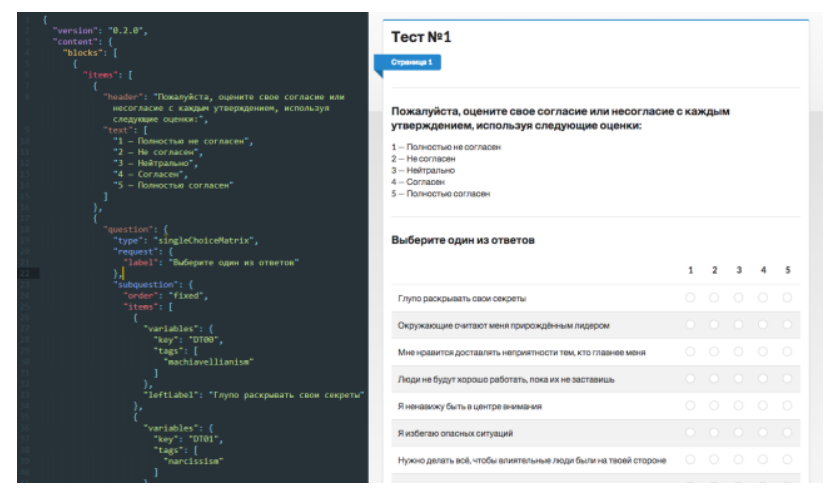

Fig. 6. Example of Test Implementation (on the Left - the Standard for the Elements Description, on the Right - the Generated Interface).

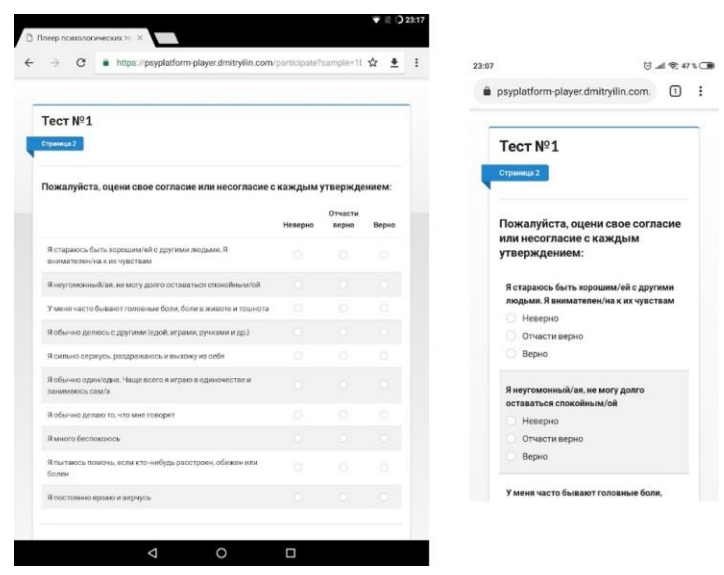

Fig. 7. Example of Respondents Questionnaires Interface Generating on Different Devices (Tablet is on the Left and Smartphone is on the Right).

\section{CONCLUSION}

Based on the analysis of the specific functions of social networks in the field of health care, the following features were identified. When targeting the mass use of platforms, there are requirements to restrict access in accordance with professional specialization. This is due to the requirements of professional ethics [24] and rules of access to medical data [25], which makes communication difficult. Thus, although the purpose of portals is to collect and consolidate disparate data, but the motivation of each individual specialist must be high. For each user, the portal data is not fully available. Often there is information that is beyond the scope of scientific or professional interest. Simply filling any data to the system does not motivate specialists, especially in the context of limited communications that are typical for health care field. It needs to develop digital tools for increasing the level of competence and work automation of each user.

The paper presented two tools aimed at developing the motivation of medical specialists to use social networks. These tools include followings: e-learning services aimed at improving skills and increasing the status of proven skills of users of social networks, advanced tools for creating surveys in the field of health. The developed tools are aimed to be used in form of Web service and can be integrated into specialized online health systems. During the testing system developing, the algorithmic standard was developed for describing the interface elements of the questionnaires. This standard will allow to implement cross-platform visualization technology that can generate a Web interface in popular browsers and popular operating systems on different devices.

\section{ACKNOWLEDGMENT}

The work was financed by Russian Foundation for Basic Research: project 17-29-02198.

\section{REFERENCES}

[1] R. Heeks, "Health information systems: Failure, success and improvisation", International Journal of Medical Informatics, vol. 75, no. 2, 2006, pp. 125-137.

[2] D. R. Kaufman, J. Mirkovic \& C. Chan, eHealth literacy as a mediator of health behaviors", In Cognitive Informatics in Health and Biomedicine (Springer, Cham), pp. 271-297. 
[3] T. J. Ma \& D. Atkin, "User generated content and credibility evaluation of online health information: a meta analytic study", Telematics and Informatics, vol. 34, no. 5, 2017, pp. 472-486.

[4] M. Carpentier, G. Van Hoye, S. Stockman, E. Schollaert, B. Van Theemsche \& G. Jacobs, "Recruiting nurses through social media: Effects on employer brand and attractiveness", Journal of Advanced Nursing, vol. 73, no. 11, 2017, pp. 2696-2708.

[5] G. Bruno, F. Dengler, B. Jennings, R. Khalaf, S. Nurcan,... \& R. Silva "Key challenges for enabling agile BPM with social software" Journal of Software Maintenance and Evolution: Research and Practice, vol. 23, no. 4, 2011, pp. 297-326.

[6] Z. Hu, Z. Zhang, H. Yang, Q. Chen, \& D. Zuo, "A deep learning approach for predicting the quality of online health expert questionanswering services", Journal of Biomedical Informatics, vol. 71, 2017, pp. 241-253.

[7] V. Neville, M. Lam, \& C. J. Gordon, "The impact of elearning on health professional educators' attitudes to information and communication technology", Journal of Multidisciplinary Healthcare, vol. 8, 2015, pp. 75-81.

[8] I. V. Osipov, A. A. Volinsky, E. Nikulchev, \& A. Y. Prasikova, "Communication and Gamification in the Web-Based Foreign Language Educational System", International Journal of Web-Based Learning and Teaching Technologies, vol. 11, no. 4, 2016, pp. 22-34.

[9] T. A. Demenkova, V. S. Tomashevskaya, \& I. S. Shirinkin, "Mobile applications for tasks of distance learning", Russian Technological Journal, vol. 6, no. 1, 2018, pp. 5-19.

[10] E. Nikulchev, D. Ilin, \& E. Matishuk, "Scalable service for professional skills analysis based on the demand of the labor market and patent search", Procedia Computer Science, vol. 103, 2017, pp. 44-51.

[11] T. Mettler, "Contextualizing a professional social network for health care: Experiences from an action design research study", Information Systems Journal, vol. 28, no. 4, 2018, pp. 684-707.

[12] C. L. Ventola, "Mobile devices and apps for health care professionals: uses and benefits", Pharmacy and Therapeutics, vol. 39, no. 5, 2014, p. 356.

[13] M. J. Dutta-Bergman, "The impact of completeness and web use motivation on the credibility of e-health information", Journal of Communication, vol. 54, no. 2, 2004, pp. 253-269.

[14] R. S. Mano, "Social media and online health services: A health empowerment perspective to online health information", Computers in Human Behavior, vol. 39, 2014, pp. 404-412.
[15] S. A. Rains, \& C. D. Karmikel, "Health information-seeking and perceptions of website credibility: Examining Web-use orientation, message characteristics, and structural features of websites", Computers in Human Behavior, vol. 25, no. 2, 2009, pp. 544-553.

[16] ,K. P. Hocevar, M. Metzger, \& A. J. Flanagin, "Source Credibility, Expertise, and Trust in Health and Risk Messaging", In Oxford Research Encyclopedia of Communication, 2017.

[17] M. Salehan, D. J. Kim, \& C. Kim, "Use of online social networking services from a theoretical perspective of the motivation-participationperformance framework", Journal of the Association for Information Systems, vol. 18, no. 2, 2017, p. 141.

[18] S. V. Rehm, L. Goel, \& I. Junglas, "Information management for innovation networks - an empirical study on the "who, what and how" in networked innovation" International Journal of Information Management, vol. 36, no. 3, 2016, pp. 348-359.

[19] M. Sprenger, A. Blondiau, P. Rohner, \& T. Mettler, "Benefits of Professional Social Networks: Expectations and Design Implications for the Healthcare Domain", Proceedings of the 17th International Symposium on Health Information Management Research - ISHIMR 2015, (https://www.alexandria.unisg.ch/241955/1/ATTCFPVC.pdf).

[20] A. A. Alkhathlan, \& A. A. Al-Daraiseh, "An Analytical Study of the Use of Social Networks for Collaborative Learning in Higher Education", International Journal of Modern Education and Computer Science, vol. 9, no. 2, 2017, pp. 1-13.

[21] S. Brownson, "Embedding social media tools in online learning courses", Journal of Research in Innovative Teaching, vol. 7, no. 1, 2014, pp. 112-118.

[22] E. Nikulchev, D. Ilin, P. Kolyasnikov, V. Belov, I. Zakharov, \& S. Malykh, "Programming technologies for the development of web-based platform for digital psychological tools", International Journal of Advanced Computer Science and Applications, vol. 9, no. 8, 2018, pp. 34-45.

[23] J. L. C. Izquierdo, \& J. Cabot, "JSONDiscoverer: Visualizing the schema lurking behind JSON documents", Knowledge-Based Systems,. vol. 103, 2016, pp. 52-55.

[24] E. Vayena, M. Salathé, L. C. Madoff, \& J. S. Brownstein, "Ethical challenges of big data in public health", PLoS computational biology, vol. 11, no. 2, 2015, e1003904.

[25] J. Sligo, R. Gauld, V. Roberts, \& L. Villa, "A literature review for largescale health information system project planning, implementation and evaluation", International Journal of Medical Informatics, vol. 97, 2017 pp. 86-97. 